\title{
Ploidy of smooth muscle tumours: retrospective image analysis study of formalin fixed, paraffin wax embedded tissue
}

\author{
A Dorman, D Graham, B Curran, K Henry, M Leader
}

\begin{abstract}
The feasibility of using an image analyser, the CAS 100 , to assess the ploidy of smooth muscle tumours on formalin fixed paraffin wax embedded tissue was assessed. Various different methods of assessment were compared. A paraffin wax block of 15 leiomyomata and 13 leiomyosarcomata yielded serial sections of $3 \mu \mathrm{m}, 5 \mu \mathrm{m}$, and $7 \mu \mathrm{m}$ and a cytospin preparation (from a $50 \mu \mathrm{m}$ section). Sections and cytospin preparations were stained with Feulgen and quantified using the CAS 100 . The suitability of $1 y m-$ phocytes, previously suggested to be unsuitable as control cells in tissue sections due to the compact nature of their DNA, was assessed in sections and cytospin preparations and compared with endothelial cells, the standard alternative, on the same slide. Despite having a mean nuclear area of only $18.5 \mu \mathrm{m}^{2}$ in sections lymphocytes had a similar diploid peak-that is, $4 \cdot 1 \mathrm{pg}$-to endothelial cells (mean nuclear area $39 \mu \mathrm{m}^{2}$ ). A comparison of $3 \mu \mathrm{m}, 5 \mu \mathrm{m}$, and $7 \mu \mathrm{m}$ sections showed $5 \mu \mathrm{m}$ to be the optimal thickness. Cytospin preparations yielded histograms of superior quality than those from tissue sections. All 15 leiomyomata had a $5 \mathrm{C}$ exceeding rate of less than $0.3 \%$. Ten of 11 histologically malignant tumours had a $5 \mathrm{C}$ exceeding rate of more than 5\% (mean 14\%) in sections and cytospins. Two leiomyosarcomata that had arisen in the lower gastrointestinal tract had a mitotic rate of $\leqslant 1 / 10$ per high power fields and yielded histograms similar to those of the leiomyomata.

It is concluded that formalin fixed, parafin wax embedded tissue can be used for DNA quantification by image analysis; that tissue sections yield poorer results than cytospin preparations; that lymphocytes are reliable control cells in cytospin preparations; and that a population of cells greater than $5 \mathrm{C}$ is seen in $\mathbf{9 0 \%}$ of leiomyosarcomata.
\end{abstract}

Department of

Pathology, Royal

College of Surgeons in

Ireland, St Stephen's

Green, Dublin 2,

Ireland

A Dorman

D Graham

B Curran

M Leader

Department of Histopathology, The

Westminster Medical

School, London

K Henry

Correspondence to:

Dr A Dorman

Accepted for publication

8 February 1990 ploid stem lines. Data on proliferative activity-S phase fractions-can also be obtained. ${ }^{67}$

Two methods are currently available to quantify nuclear DNA - the more commonly used flow cytometry and also cytophotometric image analysis. This study examines the feasibility of using the CAS 100 image analyser to measure the DNA content of benign and malignant soft tissue tumours, with smooth muscle tumours as the initial model. Archival formalin fixed paraffin wax embedded tissue was used. The CAS 100 image analyser is a sophisticated digital processing system with proprietary software to perform quantitative analysis of DNA content by Feulgen staining of individual cells. Other nuclear and cytoplasmic features can also be measured. ${ }^{89}$

The image analyser has several advantages over the flow cytometer. It allows the operator to select cells for analysis and thus avoid contamination by non-malignant cell populations. Small aneuploid peaks unrecognisable by flow cytometry may thus be identified. The problem of separating doublets (two nuclei adherent and registering as a single event on the flow cytometer) from $G_{2} / M$ phase cells is eliminated by visualising the cells. It also facilitates the identification of a control cell population, such as lymphocytes or endothelial cells, which have been fixed, processed, and stained in an identical manner as the cells under analysis. Tissue architecture can also be preserved by quantifying DNA in the nuclei of cells in tissue sections. ${ }^{1011}$

Image analysis is a relatively slow process, however, with about 200 tumour cell nuclei and 40 control cell nuclei being examined in each case. Depending on the quality and cellularity of the preparation, an analysis of control and tumour nuclei takes about 30-60 minutes for each slide. Secondly, it has been shown that lymphocytes, an apparently ideal control cell (being found in most sections), have excessively compact DNA with resultant incomplete exposure of binding sites to the DNA protein binding stain Feulgen. Some workers have suggested that this renders them unsuitable as control cells. Others suggest that a correction factor may be used to establish the $2 C\left(G_{0} / G_{1}\right)$ position for cell populations under study and thus overcome this problem. This, however, is almost certainly an oversimplification. ${ }^{12-16}$

The purpose of this study was (i): to assess whether lymphocytes are acceptable as control cells and to compare lymphocytes with endothelial cells in this respect; (ii) to determine the ideal section thickness to avoid cell overlap but to include the entire nucleus; (iii) to compare DNA quantitation of tissue sections with cytospin preparations and to ascertain which is the better type of preparation for this type of investigation; (iv) to establish if the CAS 100 
can be used to differentiated benign and malignant smooth muscle tumours when using formalin fixed, paraffin wax embedded material.

\section{Methods}

Fifteen leiomyomas were retrieved from the files of the department of pathology, Royal College of Surgeons in Ireland. The tissue blocks ranged in age from one to 12 years. Thirteen histologically malignant smooth muscle tumours were retrieved from the files of the Department of Pathology, Westminster Medical School, London. These tumours had previously been fully characterised immunohistochemically.

A representative tissue block from each case was selected. From each block four adjacent sections were cut at $3 \mu \mathrm{m}(\mathrm{n}=1), 5 \mu \mathrm{m}$ $(\mathrm{n}=2)$, and $7 \mu \mathrm{m}(\mathrm{n}=1)$. One of the $5 \mu \mathrm{m}$ sections was stained with haematoxylin and eosin for assessment of mitotic counts, while the remaining sections were stained with Feulgen. DNA ploidy was determined using the method described by Hedley and colleagues, with slight modifications. ${ }^{1718}$

Forty lymphocytes, 40 endothelial cells, and 200 tumour cells were examined on each of the four slides of every case. Only tumour cells with nuclei, four times greater in length than width, were analysed so as to include all or nearly all of the nucleus. DNA ploidy was illustrated graphically on a histogram with cell count on the vertical axis and DNA content in picograms on the horizontal axis. The $\mathrm{G}_{0} / \mathrm{G}_{1}$ peak (DNA index $=1$ ) obtained from the control cells was used to set the $G_{0} / G_{1}$ position of the study population. Subsequently, aneuploid stem lines were identified.

\section{Results}

ACCEPTABILITY OF LYMPHOCYTES AS CONTROI CELLS

In tissue sections the lymphocyte nuclear area was $18.5,17.9$, and 19.8 in $3 \mu \mathrm{m}, 5 \mu \mathrm{m}$, and $7 \mu \mathrm{m}$ sections, respectively (table 1 ). Thus the nuclear area was considerably less than the nuclear area considered to be necessary for optimal Feulgen binding and thus accurate DNA assessment. In cytospin preparations, however, the lymphocytes expanded to a mean nuclear area of $37.6 \mu \mathrm{m}^{2}$ thus overcoming this problem. Lymphocytes are thus suitable for use as control cells in cytospin preparations of paraffin wax embedded material.

COMPARISON LYMPHOCYTES AND ENDOTHELIAL CELLS AS CONTROL CELLS (table 1)

Nuclear DNA mass of lymphocytes varied between $0 \%$ and $13 \%$ less than that of endothelial cells using tissue sections. In cytospin preparations, however, the lymphocytes expanded to a mean nuclear area of $37.6 \mu^{2}$ compared with a mean nuclear area of $63.5 \mu^{2}$ in endothelial cells. Both lymphocytes and endothelial cells have sufficient nuclear area for consistent Feulgen binding and thus can be used as reliable control cells in cytospin preparations. If assessing a tumour cell population of spindle cells, however, the difficulty of
Table 1 Comparison of nuclear size and DNA mass of lymphocytes and endothelial cells

\begin{tabular}{|c|c|c|c|}
\hline \multicolumn{2}{|c|}{ Endothelial cells ( $n=28$ ) } & \multicolumn{2}{|c|}{ Lymphocytes $(n=28)$} \\
\hline $\begin{array}{l}\text { Nuclear area } \\
\left(\mu^{2}\right)\end{array}$ & $\begin{array}{l}\text { DNA mass } \\
\text { (pg) }\end{array}$ & $\begin{array}{l}\text { Nuclear area } \\
\left(\mu^{2}\right)\end{array}$ & $\begin{array}{l}D N A \text { mass } \\
(\mathrm{Pg})\end{array}$ \\
\hline $\begin{array}{l}36 \cdot 5 \\
42 \cdot 4 \\
41 \cdot 1 \\
63 \cdot 5\end{array}$ & $\begin{array}{l}4 \cdot 2 \\
4 \cdot 2 \\
4 \cdot 6 \\
5 \cdot 3\end{array}$ & $\begin{array}{l}18.5 \\
17.9 \\
19.8 \\
37.6\end{array}$ & $\begin{array}{l}4 \cdot 2 \\
4 \cdot 0 \\
4 \cdot 0 \\
5 \cdot 8\end{array}$ \\
\hline
\end{tabular}

distinguishing endothelial cells from tumour spindle cells makes lymphocytes more useful. When assessing tissue sections it is difficult to be certain that all the endothelial cell nucleus is included due to the three-dimensional coiling of endothelial cells. For this reason the use of such cells as control cells also poses problems.

\section{IDEAL SECTION THICKNESS (fig 1 )}

When $3 \mu \mathrm{m}$ sections were examined many events registered to the left of the $G_{0} / G_{1}$ peak. This was due to incomplete nuclei being assessed. When $7 \mu \mathrm{m}$ sections were studied, nuclear overlap was such that 200 tumour cells could only be found with great difficulty. Sections $5 \mu \mathrm{m}$ in thickness gave the best compromise-that is, relatively little nuclear overlap and fewer readings to the left of the $G_{0} /$ $G_{1}$ peak.

\section{CYTOSPIN PREPARATIONS COMPARED WITH} TISSUE SECTIONS (fig 2)

Tumour cells prepared from cytospin preparations containing a discrete aneuploid or tetraploid stemline, when examined using $5 \mu \mathrm{m}$ tissue sections, showed blurring of the DNA distribution between the $2 \mathrm{C}$ and $4 \mathrm{C}$ range. The resulting coefficient of variation $(\mathrm{CV})$ of diploid and aneuploid peaks was therefore
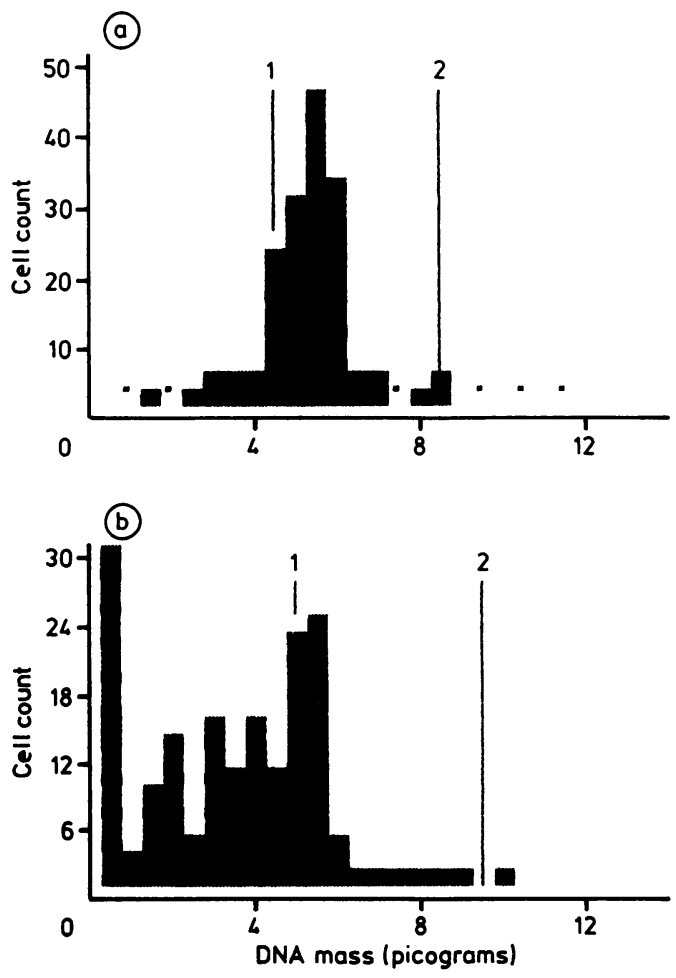

Figure 1 Histograms of $3 \mu \mathrm{m}$ ( a) and $7 \mu \mathrm{m}$ (b) sections of a leiomyoma with DNA mass in picograms on the horizontal axis. 

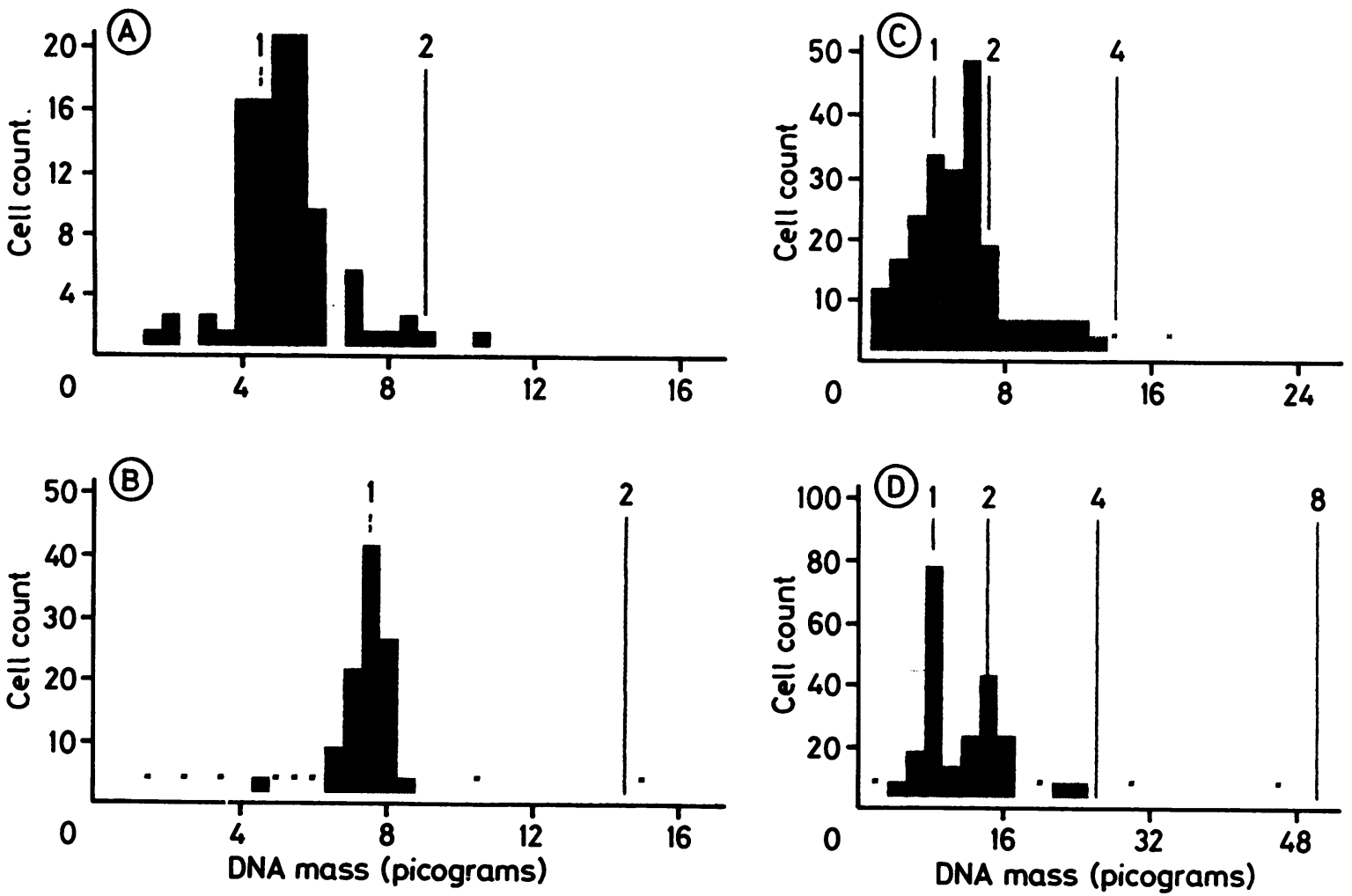

Figure 2 Comparison of tissue sections and cytospin preparations. Interpretation of the tissue section and cytospin preparation of a leiomyoma ( $a$ and $b$ ) shows a diploid pattern. The presence of a discrete tetraploid population in the cytospin preparation of leiomyosarcoma $(d)$ is blurred when a corresponding tissue section is analysed $(c)$.

lower with cytospin preparations than with tissue sections.

THE 5C EXCEEDING RATE (table 2)

This was used to compare benign and malignant smooth muscle tumours. The $5 \mathrm{C}$ exceeding rate is defined as the percentage of cells whose nuclei contain more than 5 sets of 23 chromosomes. None of the lymphocyte and endothelial cell populations yielded nuclei exceeding 5C. Benign smooth muscle tumours showed a mean $5 \mathrm{C}$ exceeding rate of less than $0.3^{\circ}$ o (range $0-0.6 \%$ ). Ten of 13 malignant smooth muscle tumours showed a $5 \mathrm{C}$ exceeding rate of more than $5 \%$ (range $5-35 \%$ ). Of the three malignant tumours with a low $5 \mathrm{C}$ exceeding rate, one had a high mitotic rate $-\geqslant 3$ per 10 high power fields-but two had a low mitotic rate. The latter two were histologically bland tumours but had been diagnosed as malignant due to their occurrence in the lower gastrointestinal tract. ${ }^{19}$

\section{Discussion}

With advances continually being made in the treatment of malignant disease, especially in the field of chemotherapy, it is becoming more important to identify subgroups of patients who might benefit from this type of aggressive treatment. The time honoured methods of prognostic assessment such as tumour grading and staging are now being reassessed and compared with studies of tumour kinetics. DNA analysis, and oncogene expression. It is of the utmost importance, however, that these newer investigative methods undergo stringent evaluation before being recommended for clinical practice.

The purpose of this study was to examine the feasability of using the CAS 100 image analyser in estimations of DNA ploidy in benign and malignant smooth muscle tumours and to investigate its ability to discriminate between the two groups. Using this relatively new instrument a number of technical problems had to be resolved. As in any investigation it is essential to have proper controls. With this in mind our study compared lymphocytes with endothelial cells and found that lymphocytes have as many advantages as control cells: (i) they are present in most tumours, where they are easily identified and separated from tumour cells (other than low grade lymphomas); (ii) they are preferable to endothelial cells as the latter coil in three dimensions along blood vessels, thus rendering some of the nucleus unavailable for quantitation-this results in higher CVs for endothelial cells and documents many events to the left of the $G_{0} / G_{1}$ peak ("rubbish content"). The resulting histogram is usually uninterpretable. Endothelial cells

Table 2 A significant 5C exceeding rate is not seen in leiomyomata but is seen in 10 of 13 leiomyosarcomata

\begin{tabular}{|c|c|c|c|c|c|c|}
\hline & \multicolumn{4}{|c|}{$5 C$ exceeding rate } & \multicolumn{2}{|c|}{ Review of histological diagnosis } \\
\hline & $3 \mu m$ & $5 \mu m$ & $7 \mu m$ & Cytospin & $5 C$ exceeding rate & Mitotic count \\
\hline $\begin{array}{l}\text { Lymphocytes }(n=28) \\
\text { Endothelial cells }(n=28) \\
\text { Benign tumours }(n=15) \\
\text { Malignant tumours }(n=13)\end{array}$ & $\begin{array}{c}0 \\
0 \\
0 \cdot 1 \\
13 \cdot 7\end{array}$ & $\begin{array}{l}0 \\
0 \\
0 \cdot 2 \\
12 \cdot 0\end{array}$ & $\begin{array}{c}0 \\
0 \\
0 \cdot 6 \\
14 \cdot 6\end{array}$ & $\begin{array}{c}0 \\
0 \\
0 \cdot 3 \\
14 \cdot 7\end{array}$ & $\begin{array}{l}15 \text { of } 15 \text { benign }<0.3 \% \\
10 \text { of } 13 \text { malignant }>5 \% \\
1 \text { of } 3 \text { malignant }<5 \% \\
2 \text { of } 3 \text { malignant }<5 \%\end{array}$ & $\begin{array}{l}\leqslant 1 \text { per } 10 \mathrm{HPF} \\
\geqslant 3 \text { per } 10 \mathrm{HPF} \\
\geqslant 3 \text { per her } 10 \mathrm{HPF} \\
\leqslant 1 \text { per } 10 \mathrm{HPF}\end{array}$ \\
\hline
\end{tabular}


also cause difficulty in that they are indistinguishable from spindle shaped tumour cells in cytospin preparations.

It has been suggested that lymphocytes cannot be used as a control cell because the nucleus is too compact for stoichiometric Feulgen binding. In tissue sections the lymphocytes tend to measure less than $20 \mu \mathrm{m}^{2}$. During the preparation of cytospins hydration enlarges the nuclei. When the nuclear area is below $20 \mu^{2}$ the apparent DNA mass is less than endothelial or benign tumour cells by a degree that is inconsistent. When the area is greater than $25 \mu^{2}$ it is consistently similar to endothelial cells and benign tumour cells and permits consistent DNA binding to Feulgen. Between $20 \mu^{2}$ and $25 \mu^{2}$, significant differences may occasionally be seen. The results of this study show, however, that as the lymphocyte nucleus consistently enlarges to more than $25 \mu^{2}$ in cytospin preparations this problem is overcome. The data presented in this study indicate their suitability and reliability as control cells in cytospin preparations using the methods described.

The second aim of this study was to determine the ideal section thickness to avoid cell overlap but to include the entire nucleus. There are many occasions when it is desirable to maintain preservation of tissue architecture and thus to examine tissue sections rather than cytospin preparations, such as the assessment of intraepithelial neoplasia, melanocytic lesions, and neoplastic lesions with a large stromal component. Morphometric quantitation of tissue sections requires an optimal thickness to ensure the intact nucleus is measured by the image analyser. The balance between including the entire nucleus, identifying sufficient isolated nuclei, and avoiding overlapping nuclei has been achieved by examining $5 \mu \mathrm{m}$ sections. Section thickness, however, may vary for different tumour types.

$S$ phase analyses and identification of hypodiploid and aneuploid populations between $2 \mathrm{C}$ and $4 \mathrm{C}\left(\mathrm{G}_{0} / \mathrm{G}_{1}\right.$ and $\mathrm{G}_{2} / \mathrm{G}_{\mathrm{M}}$ peaks $)$ are extremely difficult to identify when analysing tissue sections. The reasons are twofold. Firstly, it is difficult to obtain optimal alignment of the malignant nuclei. Secondly, in the presence of an aneuploid stem line between 2C and $4 \mathrm{C}$, those nuclei which are only partially included will register a DNA mass to the left of their correct position by a degree proportional to the amount not included in the section. This results in an obscure yet definitely abnormal and potentially confusing pattern between $G_{0} /$ $G_{1}$ and $G_{2} / M$. As an alternative to determining $S$ phase some workers have instead used a different index-namely, the 5C exceeding rate. ${ }^{2021}$ The $5 \mathrm{C}$ exceeding rate determines the number of cells which have more than five sets of 23 chromosomes-that is, DNA mass two and a half times greater than that of the $G_{0} / G_{1}$ peak. The results of this study show that the $5 \mathrm{C}$ exceeding rate can be used to separate benign from malignant smooth muscle tumours as a 5C exceeding rate is found in most malignant smooth muscle tumours and is not seen in benign tumours. Further work is required to establish whether an exceeding rate between $2 \mathrm{C}$ and $5 \mathrm{C}$ would give similar results.
In summary, DNA quantitation of formalin fixed, paraffin wax embedded smooth muscle tumours is feasible by the CAS 100 . Using lymphocytes as control cells in cytospin preparations and by carefully identifying the tumour cells for analysis useful discriminatory data can be achieved. Further studies are required to assess larger numbers of tumours and to attempt to overcome some of the problems associated with tissue sections. It would seem that image analysis, using the CAS 100 system and cytospin preparations, however, has important advantages over flow cytometry in that the problem of contaminating tumour cells is overcome, doublets do not present a difficulty and the control cells used have been treated exactly the same as the tumour cells under study. This investigation suggests that when studying tissue sections using current hydration techniques, lymphocytes have an underestimated DNA content in an inconsistent manner. They are therefore unsuitable as control cells. Endothelial cells, however, can be used as control cells in tissue sections, provided the nucleus is very carefully aligned.

Trojani M, Contesso G, Coindre JM, et al. Soft tissue sarcomas of adults: Study of pathological prognostic variables and definition of a histopathological grading system. Int J Cancer 1984;33:37-42.

2 Tsijimoto M, Aozasa K, Ueda T, Morimura Y, Komatsubara Y, Doi T. Multivariate analysis of histologic prognostic factors in soft tissue sarcomas. Cancer 1988, 62:994-8.

3 Ooms EC, Anderson WAO, Alans CL, Boon ME, Veldhuizer RW. Analysis of the performance of pathologists in the grading of bladder tumours, an ECOG study. Hum Pathol 1983;14:140.

4 Sadler PA, Coghill SB. Histopathologists, malignancies and undefined high power fields. Lancet 1989;i:785-6.

5 Graem N, Helweg-Larsen K. Mitotic activity and delay in fraem N, Helweg-Larsen K. Mitotic activity and delay in (Sect $A$ ) 1979;487:375-8.

6 Hall TC, Fu YS. Applications of quantitative microscopy in tumour pathology. Lab Invest 1985;53:5-21.

7 Quirke P, Dyson JED. Flow cytometry: Methodology and applications in pathology. $J$ Pathol 1986;149:79-87.

8 Yasnoff WA, Nayer DA, Mahran HE, Bacus SS, Bacus JW Marder RJ. An image analysis system for quantification of cellular DNA content; CAS 100, QDA. Med Info 1986.

9 De Cresce R. The CAS 100: A computerised microscopic image analysis system. Lab Med 1986;17:163-5.

10 Kreichbergs A, Zetterberg A. Cytophotometric DNA measurements of chondrosarcoma (methodologic aspects of measurements of tissue sections from old paraffin of measurements of tissue sections from old paraffin
embedded specimens). Anal Quant Cytol Histol 1980;2:84-92.

11 Bins M, Poppema S. DNA measurements in thin sections of lymphomas. Anal Quant Cytol Histol 1985;7:315-19.

2 Deitch AD, Wagner D, Richart RM. Conditions influencing the intensity of the Feulgen reaction. $J$ Histochem Cytochem 1988;16:371-9.

3 Hale AJ. The leucocyte as a possible exception to the theory of deoxyribonucleic acid constancy. J Pathol Bacterio 1963;85:311-26.

14 Mirsky AE, Ris $\mathrm{H}$. Variable and constant components of chromosomes. Nature 1949;163:666-7.

15 Mayall BH. Deoxyribonucleic acid cytophotometry of stained human leukocytes. 1. Difference among cell types. J Histochem Cytochem 1969;17:249-57.

16 Garcia AM. Studies on deoxyribonucleic acid in leukocytes and related cells of mammals vi; The Feulgen-deoxyand related cels of mammals content of rabbit leukocytes after hypytoni

17 Hedley DW, Friedlander ML, Taylor JW, Rugg CA, Musgrove EA. Methodology for analysis cellular DNA content of paraffin embedded pathologic material using content of paraffin embedded pathologic material using flow cytometry. J Histochem Cytochem 1983;31:1333-35. tissue: Five years on. Cytochem 1989;10:219-41.

tissue: Five years on. Cytochem 1989;10:219-41. Evans HL. Smooth muscle tumo
tract. Cancer 1985;56:2242-50.

20 Auer GA, Askensten H, Erhardt K, Fallenius A, Zetterberg A. Comparison between slide and flow cytophometric DNA measurements in breast tumours. Anal Quant Cytol Histol 1987;9:138-46.

1 Askensten U, Von Rosen AK, Nilson RS, Auer GU. Intratumoral variation in DNA distribution patterns in mammary adenocarcinomas. Cytometry 1989;10:326-33. 